\title{
Short-term Storage of Seeds and Cryopreservation of Embryonic Axes of Lepisanthes fruticosa
}

\author{
B. Suryanti ${ }^{*}$, M. A. Mohd Shukri ${ }^{1}$, U. R. Sinniah ${ }^{2}$, S. Nur Atisha ${ }^{1}$ \\ and A. K. Abdul Muhaimin ${ }^{3}$ \\ ${ }^{1}$ Agrobiodiversity and Environment Research Centre, MyGeneBank ${ }^{T M}$ Complex, MARDI \\ Headquarters, Persiaran MARDI-UPM, 43400 Serdang, Selangor, Malaysia. \\ ${ }^{2}$ Department of Crop Science, Faculty of Agriculture, Universiti Putra Malaysia, 43400 Serdang, \\ Selangor, Malaysia. \\ ${ }^{3}$ Industrial Crop Research Centre, MyGeneBank ${ }^{T M}$ Complex, MARDI Headquarters, Persiaran \\ MARDI-UPM, 43400 Serdang, Selangor, Malaysia.
}

\begin{abstract}
Authors' contributions
This work was carried out in collaboration among all authors. Author SB designed the study, performed the laboratory work, performed the statistical analysis, wrote the protocol and wrote the first draft of the manuscript. Author MAMS assisted in planning the study and drafting the manuscript. Author URS assisted in drafting the manuscript. Authors SNA and AKAM assisted in the laboratory work. All authors read and approved the final manuscript.

Article Information

DOI: $10.9734 / A R R B / 2021 /$ v36i730404 Editor(s):

(1) Dr. Manikant Tripathi, Dr. Ram Manohar Lohia Avadh University, Faizabad, India. Reviewers:

(1) Kaouthar Bayahi, University of Tunis el Manar and National Agronomical Institute of Tunis (INAT), Tunisia. (2) Ipsita Kar, OUAT, India. Complete Peer review History: https://www.sdiarticle4.com/review-history/71367
\end{abstract}

\section{ABSTRACT}

Aims: This work highlights short-term storage of recalcitrant Lepisanthes fruticosa seeds and longterm conservation attempts of its embryonic axes (EAs) through cryopreservation.

Study design: This study adopted the Completely Randomized Design (CRD). Ten samples were used for each experiment and replicated for $3-5$ times.

Place and Duration of Study: Cryopreservation Laboratory, Agrobiodiversity and Environment Research Centre, MARDI Headquarters, Malaysia, in 2017 and 2018.

Methodology: Short-term storage was carried out using fresh seeds at $54 \%$ moisture content and stored at $8 \pm 1{ }^{\circ} \mathrm{C}$ and $25 \pm 2{ }^{\circ} \mathrm{C}$ for 7 weeks. Three variations to sterilization were attempted to optimize survival while keeping contamination low. Cryopreservation using two different methods 
were tested, namely vitrification and the encapsulation vitrification method. Vitrification technique involved the pre-culturing of EAs overnight in different sucrose pre-culture concentrations $(0,0.2$, 0.4 and $0.6 \mathrm{M}$ ) prior to, loading, dehydration with vitrification solution (PVS2), rapid immersion into liquid nitrogen $\left(-196^{\circ} \mathrm{C}\right)$, rapid warming, unloading and recovery. While, encapsulation vitrification involved encapsulation of the EAs using $3 \%$ sodium alginate followed by exposure to different duration $(0,10,20,30,40$ and 50 minutes) of vitrification solution (PVS2) prior to cryopreservation.

Results: $L$. fruticosa seeds can be safely stored for short-term up to 7 weeks of storage either at $8 \pm 1{ }^{\circ} \mathrm{C}$ or $25 \pm 2{ }^{\circ} \mathrm{C}$ with no loss in germination. This study also showed that EA was amenable to cryopreservation and $13.33-66.67 \%$ of viability was obtained when the EAs were cryopreserved using the vitrification technique. The best result was obtained with $66.67 \%$ viability, when the EAs were pre-cultured with $0.4 \mathrm{M}$ sucrose prior to exposure to PVS2 and liquid nitrogen. Cryopreservation of EAs using the encapsulation-vitrification method was unsuccessful.

Conclusion: Seeds of $L$. fruticosa can be stored for short-term (up to 7 weeks) using hydrated/nondried seeds where they can be successfully stored at $8 \pm 1^{\circ} \mathrm{C}$ and $25 \pm 2{ }^{\circ} \mathrm{C}$ for up to 7 weeks. For long-term (cryopreservation), EAs can be cryopreserved upon pre-culture with $0.4 \mathrm{M}$ sucrose prior to exposure to PVS2 and liquid nitrogen through vitrification technique.

Keywords: Recalcitrant seeds; seed storage; cryopreservation; embryonic axes.

\section{INTRODUCTION}

Ceri Terengganu or Lepisanthes fruticosa is an underutilised tropical fruit tree from the family Sapindaceae. It can be found in Southeast Asia regions such as Malaysia, Thailand, Indonesia, Myanmar, Indo-china and Borneo. In Malaysia, the species grows naturally in forest mainly in the state of Johor and Terengganu [1]. The trees are rarely cultivated and predominantly used as ornamental tree due to its aesthetic values that lies on the attractive tree shape, light purple young foliage and long purple inflorescence which then turns into clusters of remarkable shiny bright red fruits [2]. Based on the ethnobotanical studies, this species is used in traditional medicine by rural folks. The seeds are consumed roasted, the roots are used in a compound for treating itchiness and to reduce body temperature during fever. Fruits are rich in antioxidants and the activity value is reportedly higher compared to that of popular commercialized fruits such as guavas, oranges and apples by several folds [3]. The fruit can be consumed fresh when fully ripened [1] or converted into juices. This species has future prospect to be exploited for commercial production by farmers in Malaysia due to its bioactivity, nutritional values and uses.

In view of its importance and potential, conservation methods of the genetic materials should be developed to prevent the species from extinction. Determination of a suitable method to store the seeds will be useful for researchers and growers who are working with this species. Till date, little information is available on seed storage of $L$. fruticosa. Previous study conducted at our laboratory, revealed that seeds of this species had low tolerance to desiccation where drastic reduction in the germination percentages was observed from $100 \%$ (fresh seeds) to 90,83 and $17 \%$ as the seeds were dried to the moisture content of 50,40 and $30 \%$ respectively [4]. Hence, it is clear that $L$. fruticosa belong to the recalcitrant type, and desiccation below $40 \%$ is deleterious. Storing recalcitrant seeds is difficult, dry storage is impossible due to the sensitivity towards desiccation and wet storage is also difficult because the temperature must be low enough to prevent germination, but not too low causing chilling injury. The success of recalcitrant seed storage is highly influenced by the technique used and the species characteristics. A universal method for long-term storage is yet to be established for majority of recalcitrant seeds. Hence, it is essential to identify feasible storage method for every recalcitrant seed species as response to storage is species-specific. Therefore, it is of utmost importance that storage related research is attempted to establish both short-term as well as long-term storage methods. Since preliminary studies with $L$. fruticosa seeds shows sensitivity to desiccation, the first part of this research looks into the establishment of short-term storage based on the ability of maintaining seed viability at high moisture content. This was done by looking at the effect of storing fresh seeds with high moisture content at two different temperatures on its storability and germination. Seeds stored under the above-mentioned conditions are still metabolically active and metabolism-related deterioration will unavoidably 
accumulate and adversely affect seed viability. Therefore, recalcitrant seeds cannot meet the purpose of long-term conservation of genetic resources [5]. Generally, genetic resources conservation of species with recalcitrant seeds is carried out by maintaining live plants at field germplasm or arboretum. In addition to the requirement of large space and high labour cost, field collection is exposed to loss due to deforestation and natural disasters such as pests and diseases, flash floods, droughts, heat waves and extreme weather [6]. In vitro tissue culture method can be by eliminating the risk of loss due to microbial contamination, fungi, somaclonal variations and human error during subculture [7].

Cryopreservation of plant material is currently the only option available for long-term germplasm conservation of species with recalcitrant seeds [8]. Through this technique, theoretically samples can be kept viable for an unlimited period due to storage below the freezing temperature which is $196^{\circ} \mathrm{C}$ in liquid nitrogen. At this temperature, cellular divisions and metabolic process in the conserved tissues are halted thus reducing deterioration [9]. Cryopreservation technique has been established in various fields such as in medical and reproductive biology of animal. Cryopreservation application for plant tissue is usually to preserve in vitro cultures in the horticultural industry [10]. Several studies on successful cryopreservation of species with recalcitrant seeds namely Hevea brasiliensis Muell. [11], Fortunella polyandra [12], Artocarpus heterophyllus [13], Averrhoa carambola [14], Citrus jambhiri [15], Litchi sinensis [16] and Cocos nucifera [17] have been reported.

Recalcitrant species cannot be cryopreserved through seeds as they are normally large and are shed at high water content. Therefore, excised embryos or embryonic axes are commonly used as explants [18] [19]. This is mainly because of high composition of meristematic tissues with high morphogenetic potential [20], in addition to the small size. In India, embryonic axes of Madhuca indica, Manilkara hexandra and Salvadora oleoides and embryos of $A$. marmelos have been successfully cryopreserved in the Cryogenebank at the National Bureau of Plant Genetic Resources (NBPGR) New Delhi [6]. There are several protocols that have been used for cryopreserving seeds, embryonic axes and zygotic embryos including desiccation-freezing, pregrowth desiccation, encapsulationdehydration, vitrification and encapsulationvitrification [19] [21] [5] [22].
For successful cryopreservation, it is essential to avoid intracellular ice formation in the tissue during the freezing stage which can cause damage to the cell membrane. Intracellular ice formation can be avoided by removal of freezable water in the tissue. Although earlier studies focused on direct desiccation and controlled freezing methods [23] [24], recent studies have shown that vitrification-based procedure which involves chemical dehydration before freezing by exposure of samples to highly concentrated cryoprotectant solutions is more successful [25]. Vitrification is the physical process where transition of a highly concentrated aqueous solution occurs directly from the liquid phase into an amorphous or glassy state during cooling, avoiding ice crystal formation [26]. One popular example of vitrification solution that is widely used is plant vitrification solution 2 (PVS2), which is a solution containing a combination of very high concentrations of glycerol, ethylene glycol and DMSO in basal culture medium containing $0.4 \mathrm{M}$ sucrose [27]. The vitrification technique involves several important steps including pre-culture, loading, dehydration with vitrification solution (PVS2), rapid immersion into liquid nitrogen $\left(-196{ }^{\circ} \mathrm{C}\right)$, rapid warming, unloading and recovery [25]. Example of successful cryopreservation of recalcitrant species through vitrification-based technique were Parkia speciosa Hassk. [28], Hevea brasiliensis [29], Elaeis guineensis [30], Garcinia mangostana L. [31], Nephelium ramboutan-ake [32]. The encapsulationvitrification method has been reported as having advantages over traditional cryopreservation methods, and may have wider applications for germplasm conservation [33]. It involves a combination of 2 procedures which are encapsulation and vitrification. The sodium alginate beads containing explants produced through encapsulation are subjected to freezing through vitrification

This study on $L$. fruticosa is conducted with aim to establish a short-term storage method using seeds and a long-term conservation method using EAs via cryopreservation. Specifically, it is focussed on checking the feasibility of vitrification and encapsulation-vitrification methods on cryopreservation of $L$. fruticosa EAs.

\section{MATERIAL AND METHODS}

\subsection{Plant materials}

Fruits of L. fruticosa were obtained throughout the year from a 4-year-old plant at the Malaysian 


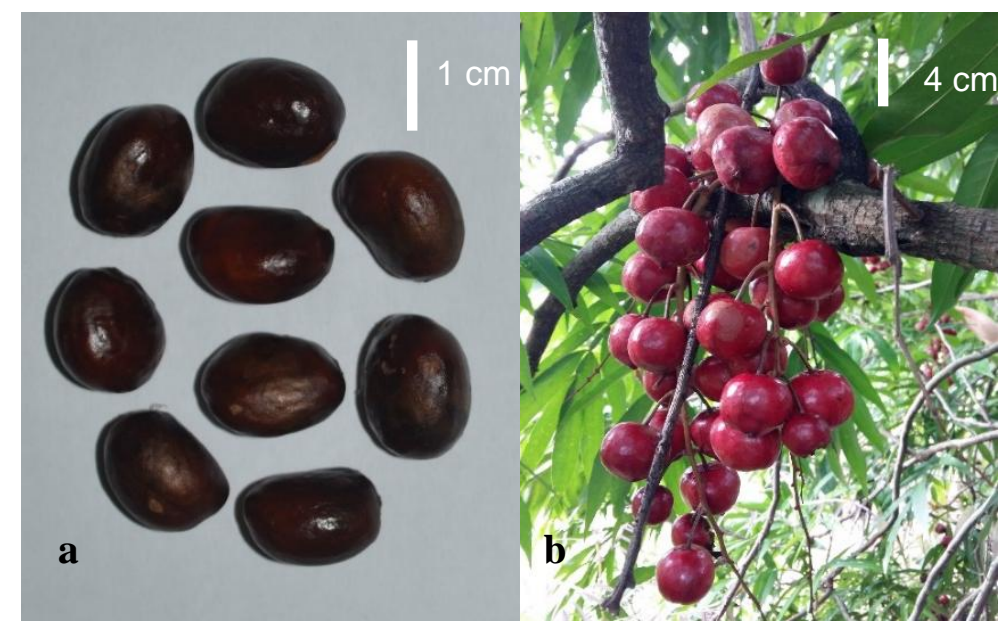

Fig. 1. Seeds and fruits of L. fruticosa. Seeds (a), Fruits (b)

Agriculture Research and Development Institute (MARDI), Serdang Field Germplasm. Seeds (Fig.1.a) were extracted from the ripe fruits (Fig.1.b) at maturity indexes $7-8$ ( 5 weeks after flower bloom). The seeds were then washed under running tap water to remove traces of flesh prior to disinfection using Dettol solution for 30 seconds. The seeds were rinsed with distilled water and subsequently blotted dry using tissue paper and were left to surface dry in the air-conditioned laboratory $\left(25 \pm 2^{\circ} \mathrm{C}, 60 \%\right.$ relative humidity) for 30 minutes.

\subsection{Methodology for Storage of Seeds}

After the seeds were extracted from freshly harvested fruits, the seeds with a moisture content of $54 \%$ were kept in an air tight container and stored in a commercial refrigerator $\left(8 \pm 1^{\circ} \mathrm{C}\right)$ and air-conditioned room $\left(25 \pm 2^{\circ} \mathrm{C}\right)$. Seeds were taken out weekly until the $7^{\text {th }}$ week of storage. Three replications of ten seeds were removed at every storage duration mentioned and sown on sterilized sand media to determine the ability to germination. The germination test was done in an air-conditioned room $\left(25 \pm 2^{\circ} \mathrm{C}, 60 \%\right.$ relative humidity). Non-stored seeds ( 0 week) were used as a control treatment. Germination percentage of seeds was recorded after 5 weeks.

\subsection{Sterilization Treatments Prior to the Culture of Embryonic Axes (EAs)}

Seeds extracted from the ripe fruits were rinsed with Dettol solution followed by sterilization with distilled water. Each seed was cut into half using a scalpel blade and the seed coats peeled. This was followed by washing under running tap water for 30 minutes, a quick wash with Dettol solution and rinse with distilled water. The seeds were then brought into the laminar air flow cabinet. Three variations were tested in this experiment, 1) seeds were surface sterilized with $30 \%$ Clorox mixed with 3 drops of Tween 20 for about 30 minutes. The seeds were washed with sterilized distilled water thrice and the embryonic axes (EAs) were then carefully excised from the seeds to $3 \mathrm{~mm}$ (length and width) sample (Fig. 2). The EAs were placed in a $50 \mathrm{ml}$ conical flask and washed with $70 \%$ ethanol for 30 second followed by $10 \%$ Clorox mixed with 3 drops of Tween 20 for 5 minutes, 2) EAs were excised first prior to surface sterilized with $30 \%$ Clorox mixed with 3 drops of Tween 20 for about 30 minutes. The EAs were washed with $70 \%$ ethanol for 30 second followed by $10 \%$ Clorox mixed with 3 drops of Tween 20 for 5 minutes, and 3) same technique was applied as in technique 1 except seeds were surface sterilized with $50 \%$ Clorox mixed with 3 drops of Tween 20 for about 15 minutes and the treatment of EAs using $10 \%$ Clorox was done for only 2 minutes. For all techniques tested, the EAs were then rinsed with sterilized distilled water thrice and blotted dry on a sterilized filter paper in a Petri dish. Ten EAs were then singly cultured into culture tubes containing full strength basal Murashige and Skoog (MS) medium [34] supplemented with myo-inositol (100 mg/L), glycine $(2.0 \mathrm{mg} / \mathrm{L})$, nicotinic acid $(0.5 \mathrm{mg} / \mathrm{L})$, pyridoxine $\mathrm{HCL}(0.5$ $\mathrm{mg} / \mathrm{L})$, thiamine $\mathrm{HCL}(0.1 \mathrm{mg} / \mathrm{L})$, ferrous sulfate $(27.8 \mathrm{mg} / \mathrm{L}), \mathrm{Na}_{2}$ EDTA ( $\left.37.3 \mathrm{mg} / \mathrm{L}\right)$ and sucrose $(20 \mathrm{~g} / \mathrm{L})$. The $\mathrm{pH}$ of the medium was adjusted at $5.7-5.8$ with $0.1 \mathrm{M} \mathrm{NaOH}$ and $0.1 \mathrm{M} \mathrm{HCL}$ and autoclaved at $121^{\circ} \mathrm{C}$ and 15 p.s.i for 15 minutes. Experiment was replicated thrice and cultures were kept under 18/6 hour photoperiod (60 $\mu$ mole $\left.\mathrm{m}^{-2} \mathrm{~s}^{-1}\right), 60 \%$ relative humidity at $25 \pm 2^{\circ} \mathrm{C}$. 


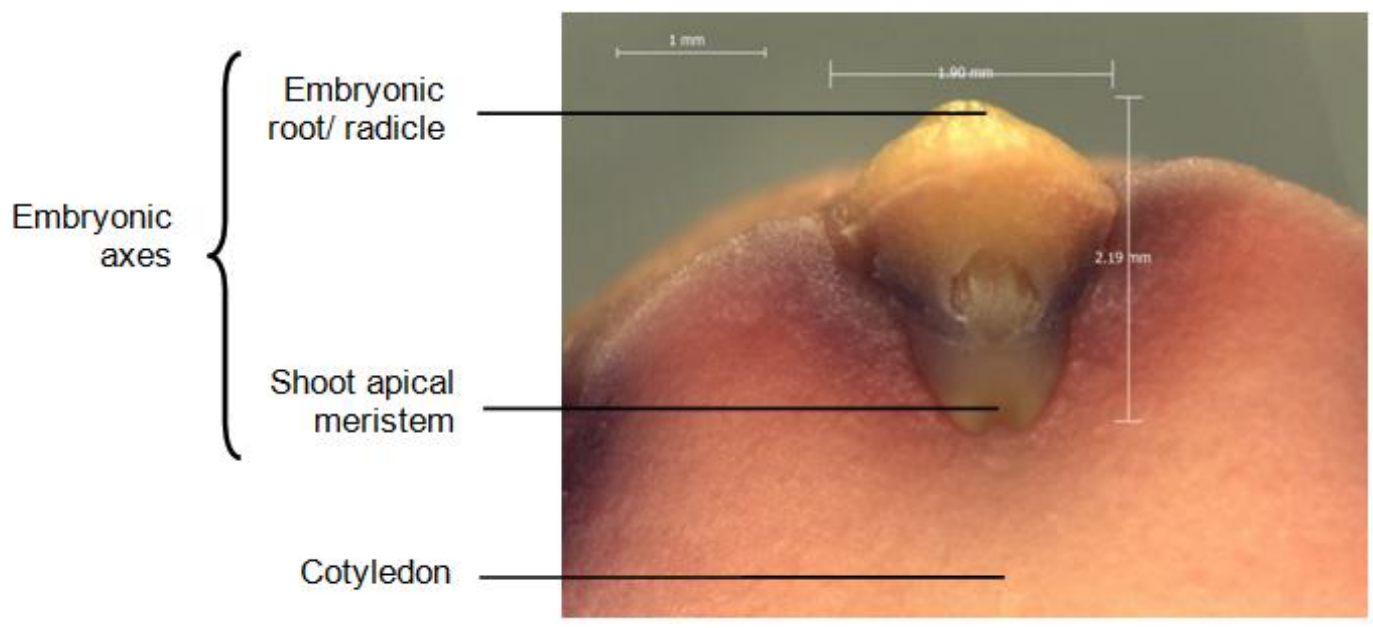

Fig. 2. View of embryonic axes (EA) through stereomicroscope upon removal of one cotyledon

Viability percentage (EAs expand and turn green) was recorded after 2 weeks while clean culture and survival percentage (EAs formed complete plantlet) was recorded after 5 weeks of culture.

\subsection{Cryopreservation of EAs through Vitrification Technique}

EAs measuring $3 \mathrm{~mm}$ (length and width) were used as the explant. The EAs were pre-cultured overnight in the dark in MS medium supplemented with $0,0.2,0.4$ and $0.6 \mathrm{M}$ sucrose. The pre-cultured EAs were then placed into the cryotubes filled with Loading solution (2 M glycerol $+0.4 \mathrm{M}$ sucrose) for 20 minutes and subsequently dehydrated with PVS2 solution [27] [2 ml: $30 \%(\mathrm{w} / \mathrm{v})$ glycerol $+15 \%(\mathrm{w} / \mathrm{v})$ ethylene glycol $+15 \%$ (w/v) DMSO-dimethyl sulfoxide + $0.4 \mathrm{M}$ sucrose, $\mathrm{pH}$ 5.8] for 5 minutes and then PVS2 solution was replaced with $2 \mathrm{ml}$ fresh PVS2 and held for $20 \mathrm{~min}$ at $0^{\circ} \mathrm{C}$ (ice bucket). The EAs in the cryotube were suspended in 0.5 $\mathrm{ml}$ PVS2 solutions, tied with cryocane and were directly plunged into Liquid Nitrogen (LN)(cryopreservation) for 1 hour. Non-LN exposed EAs were kept as control and processed in the same way as LN-exposed samples except for the exposure to LN. After LN exposure, rewarming was performed by rapidly immersing the cryotubes containing EAs in a water bath at $40^{\circ} \mathrm{C}$ for 90 seconds. PVS2 solution was replaced with washing solution (MS $+1.2 \mathrm{M}$ sucrose) twice at 10 minutes interval, blotted on filter paper layer on MS basal medium for one day and then transferred to recovery [MS medium + $0.5 \mathrm{mg} / \mathrm{L}$ BAP (6-Benzylaminopurine) $+0.1 \mathrm{mg} / \mathrm{L} \mathrm{GA}$ (gibberellic acid)] in dark. After 7 days of incubation in the dark, the EAs were transferred to standard illumination conditions. The EAs were transferred after 4 weeks to medium supplemented with $1.0 \mathrm{mg} / \mathrm{L}$ BAP (6Benzylaminopurine) and $0.5 \mathrm{mg} / \mathrm{L}$ NAA (1Naphthaleneacetic acid). Each sucrose concentration treatment consisted of 10 samples and was replicated 5 times. Viability percentage of EAs was recorded after 12 weeks.

\subsection{Cryopreservation of EAs through Encapsulation Vitrification Technique}

EAs measuring $3 \mathrm{~mm}$ were used as the explant. The EAs were encapsulated with sodium alginate (3\%; w/v) and calcium chloride $(75 \mathrm{mM})$ solution to form calcium-alginate beads. The encapsulated EAs were pre-cultured overnight in the dark in MS medium supplemented with $0.4 \mathrm{M}$ sucrose. Following which, the same process as for vitrification was used except on variations on the duration of PVS2 exposure namely $0,10,20$, 30, 40 and 50 minutes. Each duration treatment consisted of 10 samples and was replicated 5 times. Viability percentage of EAs was recorded after 12 weeks.

\subsection{Statistical Analysis}

All data were analyzed by analysis of variance (ANOVA) using Statistical Analyses System Software (SAS) release 9.4. This study adopted the Completely Randomized Design (CRD). Means was differentiated at $P=0.05$ level of significance using Tukey's Studentized Range (HSD) Test. 


\section{RESULTS AND DISCUSSION}

\subsection{Effect of Storage Temperature $\left(8 \pm 1^{\circ} \mathrm{C}\right.$ and $25 \pm 2^{\circ} \mathrm{C}$ ) on Germination of Seeds}

Germination percentage of fresh seeds stored up to 7 weeks at $8 \pm 1{ }^{\circ} \mathrm{C}$ and $25 \pm 2{ }^{\circ} \mathrm{C}$ was $100 \%$ (Fig. 3). The test in the study was done only for 7 weeks and not more than that. Thus, we have no proof to claim that there was reduction in the germination percentage over 7 weeks. The response of $L$. fruticosa seeds to storage at low temperature of $8 \pm 1{ }^{\circ} \mathrm{C}$ contradicted previous report for most tropical recalcitrant seeds which stated that storage temperatures below $15^{\circ} \mathrm{C}$ was lethal [35]. Our study proved that $L$. fruticosa seeds were not sensitive to chilling at $8 \pm 1{ }^{\circ} \mathrm{C}$. In this study, although seeds stored at $25 \pm 2{ }^{\circ} \mathrm{C}$ gave comparable results with storage at $8 \pm 1{ }^{\circ} \mathrm{C}$, however, precocious germination and fungal contamination occurred during second week of storage (data not shown). Incidence of precocious germination and microbial contamination in seeds when stored in ambient conditions beyond 18 days was also reported for other recalcitrant species namely Garcinia indica, Syzygium cumini and Madhuca indica [6]. In order to reduce contamination, the seeds can be disinfected using Dettol solution prior to germination. As recalcitrant seeds are not tolerant to desiccation, the seeds must be stored at their shedding water content, since even mild dehydration badly affects viability [36]. According to Berjak and Pammenter (2004), fungal contamination is one of the constraints of storing seeds in hydrated form and this can be reduced by cleaning and decontaminating the seeds prior and during storage [37]. Hydrated seed remain metabolically active even during storage and this often results in the precocious germination in stored recalcitrant seeds [38] [18]. To reduce the rate of metabolism and germination in hydrated recalcitrant seeds, they could be stored at low temperatures (but above zero). However, to avoid chilling injury, storage must be carried out at the lowest temperature with no adverse effects on vigor and viability [18]. Our results suggested that optimum conditions for short-term storage for $L$. fruticosa seeds is to store fresh (hydrated) seeds at low temperature of $8 \pm 1{ }^{\circ} \mathrm{C}$ as they did not show reduction on germination ability even up to 7 weeks of storage, with no occurrance of precocious germination and microbial contamination. Hydrated storage of recalcitrant seeds is strictly for short-term, either a few days for seeds of many tropical species or possibly a year or more for seeds of chilling-tolerant temperate species that can be maintained at temperatures close to zero [18]. Since $L$. fruticosa seeds recorded $100 \%$ viability after storage for 7 weeks, it has the potential to survive in storage for longer duration. The current study only tested for 7 weeks of storage; therefore, the critical storage duration was not obtained. It is suggested that prolonged storage under this condition is carried out to obtain maximum duration and the seeds can maintain their viability.

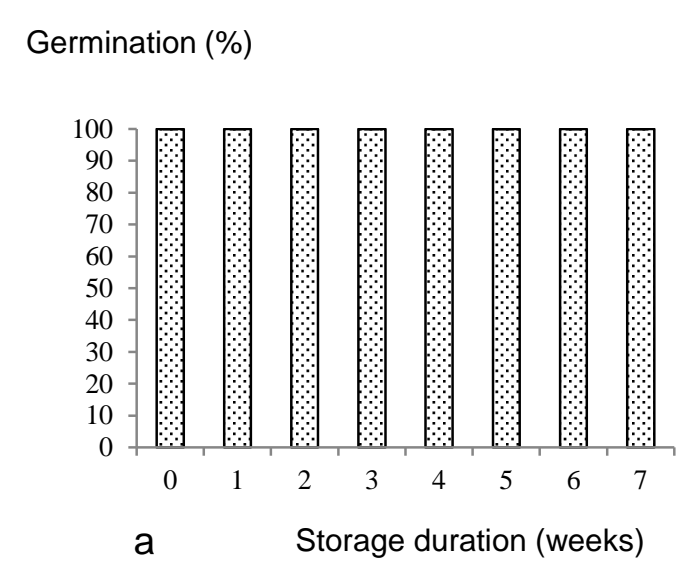

Germination (\%)

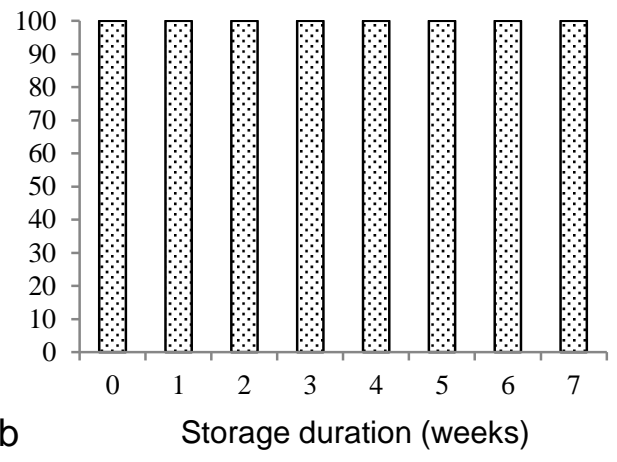

Fig. 3. Germination (\%) of fresh $L$. fruticosa seeds stored for 7 weeks at different temperature. $8 \pm 1^{\circ} \mathrm{C}(\mathrm{a}), 25 \pm 2{ }^{\circ} \mathrm{C}$ (b). Means with different letters between germination percentages are significantly different at $P=0.05$ 


\subsection{Effect of Sterilization Treatments Prior to the Culture of Embryonic Axes (EAs)}

A previous study on sensitivity towards desiccation in L. fruticosa seeds [4] made us conclude that they belong to the recalcitrant category. Thus, long-term storage for germplasm conservation via seed storage is not an option. Cryopreservation is the only feasible option to ensure longevity in storage especially for seeds that are recalcitrant in nature. It has been established that big seeds are not suitable for cryopreservation, while the zygotic embryos or embryonic axis are recommended, because of its size, desiccation can occur evenly [39]. The ability to surgically dissect out the growing portion of the seed (embryonic axis) and germinate it in vitro was a critical aspect that led to successful cryopreservation of recalcitrant species [11]. However, the growth and development of the embryonic axis in culture is influenced by sterilization process to obtain clean culture, the types and size of explant and the media. The use of different concentrations of sterilant and variations in the sterilization protocol on $L$. fruticosa had no effect on the percentage of clean culture with all treatment giving 100\% clean cultures (Fig. 4). However, the ability to produce clean culture alone cannot be a satisfactory factor to decide that a particular technique is optimum. The technique must allow the EAs to grow into complete plantlet bearing healthy shoot and root. Although technique 2 recorded full clean culture however, the explants were unable to continue growing which it recorded zero in viability and survival percentages. This might due to the injuries caused by the direct exposure of EAs to high concentration of Clorox (30\%). As the EAs have been excised from the cotyledon prior to the exposure to Clorox solutions, thus there were no mechanisms which can protect them from injuries caused by Clorox. This study also proved that $50 \%$ Clorox is harmful when directly exposed to the seeds as in technique 3 which there was no survival recorded. Treatment 1 could be considered as optimum as it resulted in $100 \%$ viability (EAs expanded and turned green) and $87 \%$ survival (EAs formed complete plantlet with normal shoot and root). Clorox contains sodium hypochlorite which act as the disinfectant agent which has a strong oxidizing property which makes it highly reactive with amino acids, nucleic acids, amines and amides, it is highly effective against all kinds of bacteria, fungi, and viruses. However, care must be taken during sterilization processes for tissue culture as direct contact of the tissue with disinfectant during the sterilization process may have a severe effect on the viability and regeneration capacity depending on concentration, temperature and application periods of disinfectant [40].

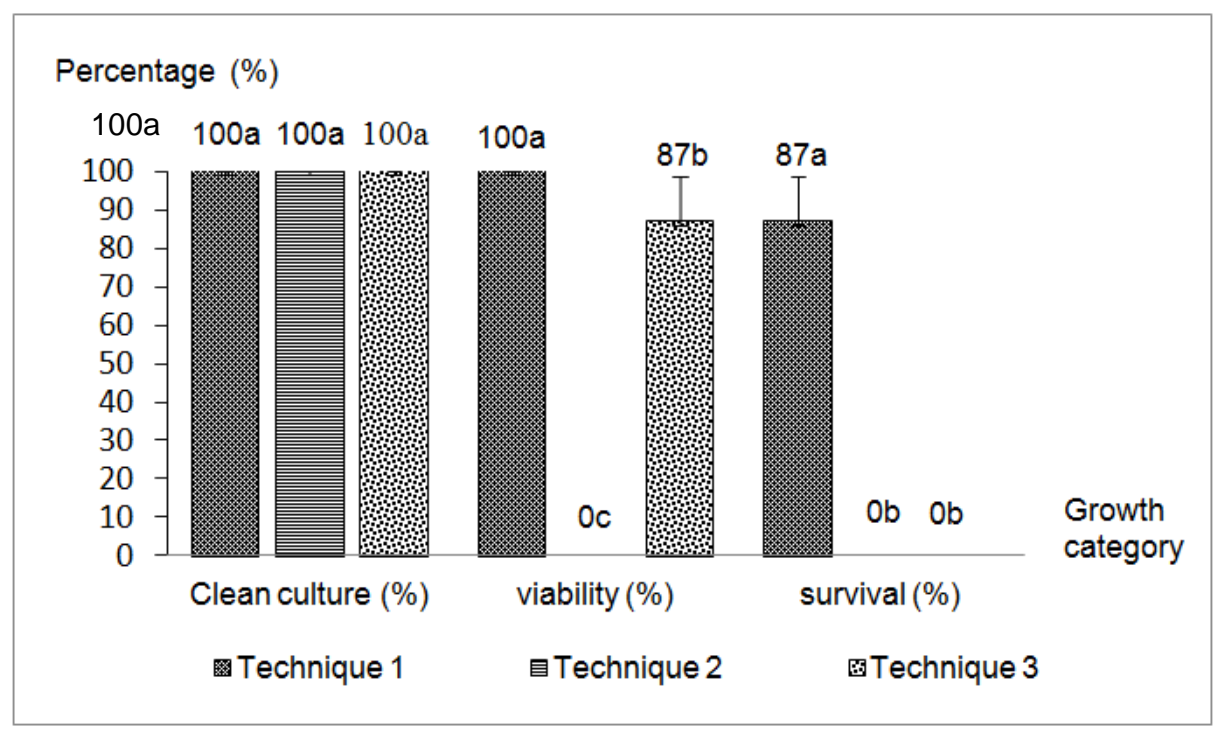

Fig. 4. The effects of variations in sterilization on percentage of clean cultures, viability and survival of embryonic axes (EAs) of $L$. fruticosa cultured on MS medium. Means with different letters within each category (clean culture, viability or survival) are significantly different at $\boldsymbol{P}=$ 


\subsection{Effect of Sucrose Pre-culture Concentrations on Cryopreservation of EAs Through Vitrification Technique}

The key for successful cryopreservation by vitrification is to optimize the steps involved in the vitrification technique. The experiments performed with $L$. fruticosa in EAs allowed comparison of two different vitrification procedures. The current study, was performed to obtain suitable concentration of sucrose as pretreatment prior to cryopreservation (Liquid nitrogen exposure/+LN) through vitrification with PVS2 solution. Based on the results in Table 1, EAs from all concentration had $100 \%$ viability without exposure to liquid nitrogen (-LN). After exposure to liquid nitrogen, the best results were obtained $(66.67 \%)$ by overnight pre-culture with $0.4 \mathrm{M}$ sucrose prior to dehydration using PVS2 solution and cryopreservation. The addition of sucrose to the pregrowth medium has proved to be the key to success in the cryopreservation method described here. The optimal sucrose concentration for $L$. fruticosa $(0.4 \mathrm{M})$ is very similar to that determined for Musa spp. meristem culture by Panis et al. but preculture of Musa spp. took 3 weeks [41] instead of only $24 \mathrm{~h}$ for $L$. fruticosa. Sucrose plays an important role for success in cryopreservation where it could potentially reduce moisture content due to osmotic action. As a result, it lowered down the freezing point and the amount of freezable water present in tissues [42] [41]. In addition, an indirect effect of sucrose could be the accumulation of endogenous compounds such as Proline induced in immature embryos of $Z$. mays by a mild osmotic stress, which then offer protection against further water stress and cryopreservation [43]. Based on Fig. 5, the growth of EAs after vitrification treatment before and after cryopreservation $(-\mathrm{LN} /+\mathrm{LN})$ were unable to produce plantlet with shoot and root but produced multiple globular embryos. This is a common phenomenon faced in cryopreservation studies where abnormal seedlings were produced in many species following cryopreservation and the conversion of these seedlings into normal plantlets remains a major challenge for many cryopreservation protocols [44] [45]. In coconut, apart from the $20 \%$ soilestablished coconut seedlings after cryopreservation, they produced a further $23 \%$ of recovered embryos which were viable. However, the embryos lacked roots or had stunted shoot and unable to produce normal plantlets [46]. Similar trend was found by Normah et al., (1986) where various abnormalities in seedling growth after cryopreservation were observed in some of the treatments [11], hence, refinement of the technique is needed. The abnormal growth produced in the current study might be due to the toxic effect of the vitrification solution at full strength $(100 \%)$ and therefore, according to Mandal (2003) care must be taken to standardize the time and temperature of treatment as precisely as possible in order to get the normal growth after cryopreservation [47].

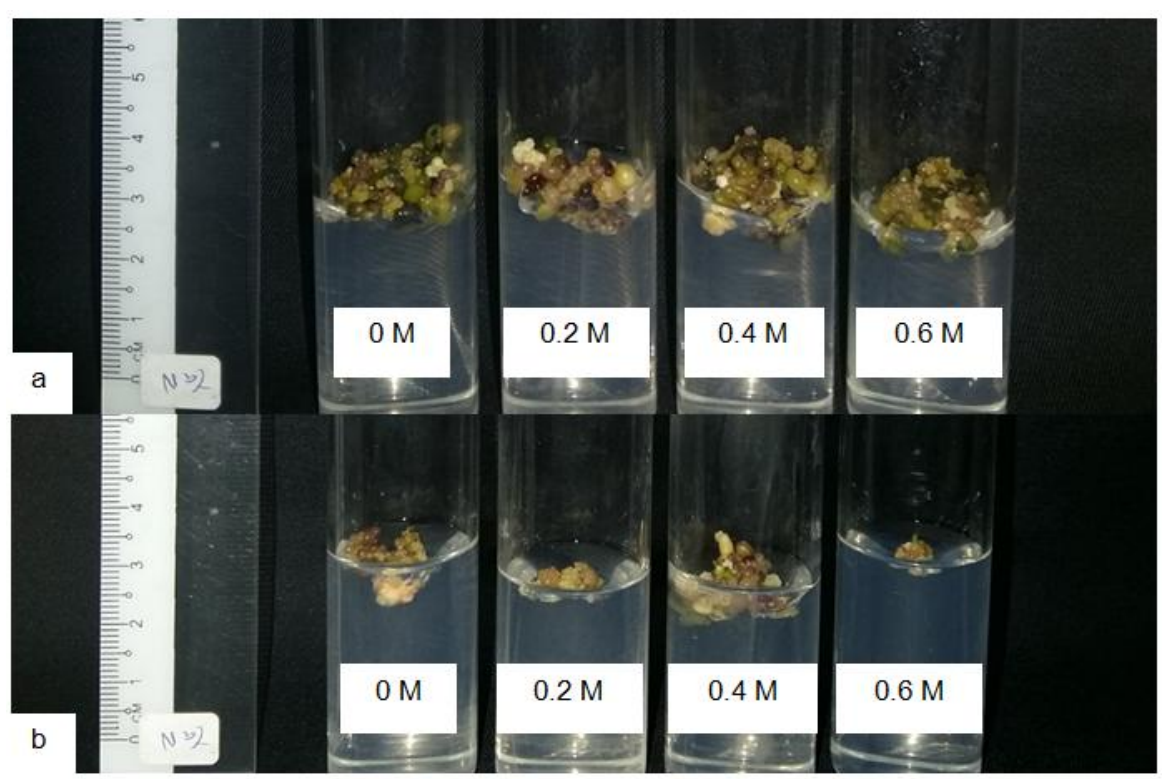

Fig. 5. The growth of EAs after vitrification treatment without cryopreservation (a), with cryopreservation (-LN/+LN) (b) after 20 weeks 
Table 1. The effect of different sucrose concentration $(0,0.2,0.4$ and $0.6 \mathrm{M})$ on the viability after 12 weeks of culture of post-cryopreserved embryonic axes through vitrification technique. Means values with different letters within the same column are significantly different at $P=0.05$

\begin{tabular}{lll}
\hline $\begin{array}{l}\text { Concentration of sucrose pre- } \\
\text { culture }\end{array}$ & \multicolumn{2}{c}{ Viability (\%) } \\
\cline { 2 - 3 } & $\begin{array}{l}\text { Without cryopreservation } \\
(-\mathrm{LN})\end{array}$ & $\begin{array}{l}\text { After cryopreservation } \\
(+\mathrm{LN})\end{array}$ \\
\hline $0 \mathrm{M}$ & $100 \pm 0 \mathrm{a}$ & $20 \pm 0 \mathrm{c}$ \\
$0.2 \mathrm{M}$ & $100 \pm 0 \mathrm{a}$ & $13.33 \pm 5.77 \mathrm{c}$ \\
$0.4 \mathrm{M}$ & $100 \pm 0 \mathrm{a}$ & $66.67 \pm 5.77 \mathrm{a}$ \\
$0.6 \mathrm{M}$ & $100 \pm 0 \mathrm{a}$ & $40 \pm 0 \mathrm{~b}$ \\
\hline
\end{tabular}

Table 2. The effect of different PVS2 exposure durations $(0,10,20,30,40$ and 50 minutes) on the viability after 12 weeks culture of post-cryopreserved embryonic axes through encapsulation-vitrification technique. Means values with different letters within the same column are significantly different at $P=0.05$

\begin{tabular}{lll}
\hline & \multicolumn{1}{c}{ Viability (\%) } \\
\hline PVS2 exposure durations & $\begin{array}{l}\text { Without cryopreservation } \\
(-\mathrm{LN})\end{array}$ & After cryopreservation (+LN) \\
\hline 0 Minutes & $100 \pm 0 \mathrm{a}$ & $0 \pm 0 \mathrm{a}$ \\
10 Minutes & $100 \pm 0 \mathrm{a}$ & $0 \pm 0 \mathrm{a}$ \\
20 Minutes & $100 \pm 0 \mathrm{a}$ & $0 \pm 0 \mathrm{a}$ \\
30 Minutes & $100 \pm 0 \mathrm{a}$ & $0 \pm 0 \mathrm{a}$ \\
40 Minutes & $100 \pm 0 \mathrm{a}$ & $0 \pm 0 \mathrm{a}$ \\
50 Minutes & $100 \pm 0 \mathrm{a}$ & $0 \pm 0 \mathrm{a}$ \\
\hline
\end{tabular}

3.4 Effect of Different duration of PVS2 Exposure on Cryopreservation of EAs Through Encapsulation Vitrification Technique

Based on Table 2, control treatment through the encapsulation-vitrification of $L$. fruticosa $E A s$ without cryopreservation recorded $100 \%$ viability for all PVS2 exposure treatment producing multiple globular embryos. However, cryopreservation through the encapsulationvitrification was unsuccessful as all of the EAs tested on different durations of vitrification solution (PVS2) exposure lost their viability after cryopreservation. This was most likely due to the high moisture content in the encapsulated propagules in order survive cryopreservation without the formation of intracellular ice crystals that can be lethal to the tissue during freezing by liquid nitrogen. Previous work by $\mathrm{Wu}$ et al., (2003) revealed that encapsulation has slowed down the dehydration processes in mango EMs and they recorded zero recovery after cryopreservation [48]. Pammenter and berjak (2014) stated that EAs require protection in the form of coating to avoid direct exposure to toxic chemical and liquid nitrogen. However, the use of such treatment is not always successful and sometimes can be detrimental [18].

\section{CONCLUSION}

L. fruticosa seeds can be stored for up to 7 weeks when freshly collected seeds are kept in air-tight container either at $8 \pm 1^{\circ} \mathrm{C}$ or $25 \pm 2{ }^{\circ} \mathrm{C}$ with $100 \%$ germination. Despite retaining high germination percentage, seeds stored $25 \pm 2{ }^{\circ} \mathrm{C}$ were amenable to fungal contamination but not at $8 \pm 1{ }^{\circ} \mathrm{C}$. Cryopreservation for conservation of L. fruticosa is possible as $66.67 \%$ viability was obtained using freshly excised EAs precultured on $0.4 \mathrm{M}$ sucrose for 24 hours prior to following the standard vitrification process. However, as this is the first study on $L$. fruticosa, further refinement to the protocol is necessary to ensure that the viable EAs can be successfully converted into healthy plantlets after exposure to liquid nitrogen.

\section{COMPETING INTERESTS}

Authors have declared that no competing interests exist. 


\section{REFERENCES}

1. Abd. Latif $\mathrm{M}$, Ahmad Zuhaidi $\mathrm{Y}$, Zawiyah $\mathrm{N}$, Nik Zanariah NM, Othman H. Sinonim nama tempat dengan nama tumbuhan. FRIM Special Publication, Kepong Malaysia. 2016;No.12:108-109.

2. Rukayah A. Buah-buahan nadir Semenanjung Malaysia, $3^{\text {rd }}$ ed. Dewan Bahasa dan Pustaka. Kuala Lumpur, Malaysia. 2006;127-129.

3. Mirfat AHS, Salma I. Ceri Terengganu. The future antioxidant superstar. MARDI Scientia. 2015;6,6: September 2.

4. Suryanti B, Noor Camellia NA, Nur Atisha $S$, Abdul Muhaimin AK, Mohd Shukri MA. Seed storage behaviour of potential fruit species (Lepisanthes fruticosa). Transaction of the Malaysian Society of Plant Physiology. elSSN 2600-9595. 2019;26:250-254.

5. Wen B, Wang $X$, Tan $Y$, Song $S$. Differential responses of Mimusops elengi and Manilkara zapota seeds and embryos to cryopreservation. In Vitro Cell. Dev. Biol. Plant. 2013;49:717-723.

6. Malik SK, Chaudhury R, Kalia RK, Dulloo E. Seed Storage Characteristics and Cryopreservation of Genetic Resources of Tropical Underutilized Fruits in India. Acta Hortic. 2011;918:ISHS.

7. Sen-Rong $H$, Ming-Hua $Y$. A simple cryopreservation protocol for in vitro-grown shoot tips of Chinese genuine red bud taro (Colocasia esculenta L. Schott Var. Cormosus CV. Hongyayu) by encapsulation-dehydration. Sci. Hortic. 2013;162:226-233.

8. Engelmann F. Cryopreservation of embryos. In: Thorpe TA, Yeung EC, editors. Plant embryo culture: Methods and protocols. Humana Press. 2011;155-184.

9. Chaudhury R. Principles of cryopreservation. In: Chaudhury R, Pandey R, Malik SK, Bhag Mal, editors. In vitro conservation and cryopreservation of tropical fruit species IPGRI Office for South Asia, New Delhi, India/NBPGR, New Delhi, India. 2003;125-131.

10. Reed BM. Plant cryopreservation: A practical guide. Springer, New York. 2008.

11. Normah MN, Chin HF, Hor YL. Desiccation and cryopreservation of embryonic axes of Hevea brasiliensis Muell. -Arg. Pertanika. 1986;9(3):299-303.

12. Al-Zoubi OM, Normah MN. Recovery medium and size of embryonic axes for cryopreservation of Fortunella polyandra. In: Sinniah UR, Ahmad I, Madom MS, Doss C, Chandrabalan D, Normah MN, Chin HF, editors. Proceedings 5th National Seed Symposium, Current trends towards quality planting materials. Universiti Putra Malaysia, Serdang. 2009;177-180.

13. Chandel KPS, Chaudhury J, Radhamani J, Malik SK. Desiccation and sensitivity in recalcitrant seeds of tea cocoa and jackfruit. Ann. Bot. 1995;76:443-450.

14. Normah MN. Current status of cryopreservation research and future perspectives of its application in Malaysia. In: Engelmann $F$, Takagi $H$, editors. Cryopreservation of tropical plant germplasm. Current research, progress and application. JIRCAS, Tsukuba, Japan/IPGRI, Rome, Italy. 2000.

15. Malik SK, Chaudhury R, Mittal M. Ex-situ conservation of citrus germplasm in cryobank. In: Singh S, Ghosh SP, editors. Hi-tech citrus management. Proc. International Symposium on citriculture. ISC/ICR/NRCC. Nagpur, India. 2000.

16. Chaudhury R, Mandal BB, Malik SK. Development of cryopreservation techniques for the long-term conservation of recalcitrant seed and vegetatively propagated plant species in India, IPGRINBPGR Project Report (1996-2000), IPGRI, Rome, Italy. 2000.

17. Assy-Bah $B$, Engelmann $F$. Cryopreservation of immature embryo of coconut (Cocos nucifera) and subsequent regeneration of plantlet. Cryo Letters. 1992;13:67-74.

18. Pammenter NW, Berjak P. Physiology of desiccation-sensitive (Recalcitrant) seeds and the implications for cryopreservation. Int. J. Plant Sci. 2014;175(1):21-28.

19. Devi SD, Kumaria S, Das MC. Development of cryopreservation protocol for Aquilaria malaccensis Lam., a recalcitrant seeded tropical tree species. Cryo Letters. 2019;40(1):18-27.

20. Malik SK, Chaudhury R, Kalia RK. Seed storage behavior and cryopreservation of tropical fruit species. In: Chaudhury R, Pandey R, Malik SK, Bhag Mal, editors. In Vitro Conservation and Cryopreservation of Tropical Fruit Species. IPGRI Office for South Asia, New Delhi, India/ NBPGR, New Delhi, India. 2003;175-190.

21. Rohini MR, Malik SK, Choudhary R, Kaur S, Uchoi A, Chaudhury R. Storage behavior and cryopreservation studies in 
Indian rough lemon (Citrus jambhiri): A promising rootstock for long-term conservation. Turk J Agric For. 2016;40(6):865-873.

22. Rajaee M, Zare AG, Shahrzad S. Cryopreservation of embryonic axes of Ferula gummosa: A tool for germplasm conservation and germination improvement. Acta Hortic. 2012;964,ISHS:153-160.

23. Wesley-Smith J, Vertucci CW, Berjak P, Pammenter NW, Crane J. Cryopreservation of desiccation-sensitive axes of Camellia sinensis in relation to dehydration, freezing rate and the thermal properties of tissue water. J. Plant Physiol. 1992;140:596-604.

24. Makeen MA, Normah MN, Dussert S, Clyde MM. Cryopreservation of whole seeds and excised embryonic axes of Citrus suhuiensis cv. Limau langkat in accordance to their desiccation sensitivity. Cryo Letters. 2005;26(4):259-268.

25. Engelmann F. Cryopreservation for Longterm Conservation of Agrobiodiversity: Progress and Prospects. Institute of System Biology UKM, Bangi, Malaysia. ISBN:983-44317-3-0. 2009.

26. Fahy GM, MacFarlane DR, Angell CA, Meriman HT. Vitrification as an approach to cryopreservation. Cryobiology. 1984;21:407-426.

27. Sakai A, Kobayashi S, Oyama I. Cryopreservation of nucellar cells of navel orange (Citrus sinensis Osb. var. Brasiliensis Tanaka) by vitrification. Plant Cell Rep. 1990;9:30-33.

28. Sinniah UR, Gantait S. Cryopreservation of immature Parkia speciosa Hassk. zygotic embryonic axes following desiccation or exposure to vitrification solution. Acta Physiol. Plant 2013;35:2629-2634.

29. Nakkanong K, Nualsri C. Cryopreservation of Hevea brasiliensis zygotic embryos by vitrification and encapsulation-dehydration. J. Plant Biotechnol. 2018;45:333-339.

30. Periasamy S, Gantait S, Sinniah UR, Subramaniam S, Alwee SSRS, Roowi SH. Effect of loading and vitrification solutions on survival of cryopreserved oil palm polyembryoids. Plant Growth Regul. 2012;66:101-109.

31. Ibrahim S, Normah MN. The survival of in vitro shoot tips of Garcinia mangostana L. after cryopreservation by vitrification. Plant Growth Regul. 2013;70(3):237-246.
32. Chua SP, Normah MN. Effect of preculture, PVS2 and vitamin C on survival of recalcitrant Nephelium ramboutan-ake shoot tips after cryopreservation by vitrification. Cryo Letters. 2011;32(6):506515.

33. Hirai D, Sakai A. Cryopreservation of in vitro-grown axillary shoot-tip meristems of mint (Mentha spicata L.) by encapsulation vitrification. Plant Cell Rep. 1999;19:150155.

34. Murashige S, Skoog F. A revised medium for rapid growth and bio assays with tobacco tissue cultures. Physiol. Plant. 1962;15(3):473-497.

35. Bedi S, Basra AS. Chilling injury in germinating seed: Basic mechanism and agricultural implications. Seed Sci. Res. 1993;3:219-229.

36. Eggers S, Erdey D, Pammenter NW, Berjak P. Storage and germination responses of recalcitrant seeds subjected to mild dehydration. In: Adkins S, Ashmore S, Navi SC, editors. Seed biology: Development and ecology. CABI, Wallingford. 2007;85-92.

37. Berjak P, Pammenter NW. Recalcitrant seeds. In: Benech-Arnold RL, Sa'nchez RA, editors. Handbook of seed physiology: Applications to agriculture. Haworth, New York. 2004;305-345.

38. Berjak P, Farrant JM, Pammenter NW. The basis of recalcitrant seed behaviour. In: Taylorson RB, editor. Recent advances in the development and germination of seeds. Plenum, New York, 1989;89-108.

39. Chin HF, Krishnapillay B, Alang ZC. Cryopreservation of Veitchia and Howea palmembryos: non-development of the haustorium. Cryo Letters. 1988;9:372-379.

40. Yildiz Y, Ozcan SF, Kahramanogullari CT, Tuna E. The effect of sodium hypochlorite solutions on the viability and in vitro regeneration capacity of the tissue. The Natural Products Journal. 2012;2(4):328331.

41. Panis B, Totté N, Nimmen KV, Withers LA, Swennen R. Cryopreservation of banana (Musa spp.) meristem cultures after preculture on sucrose. Plant Sci. 1996;121:95-106.

42. Uragami A, Sakai A, Nagai M. Cryopreservation of asparagus (Asparagus officinalis L.) cultured in vitro. Jpn. Agric. Res. Q. 1993;27(2):112-115.

43. Delvalléé I, Guillaud J, Beckert M, Dumas C. Cryopreservation of immature maize 
embryos after freeze-hardening in the ear and in vitro. Plant Sci. 1989;60:129-136.

44. Peran R, Berjak P, Pammenter NW, Kioko $\mathrm{JL}$. Cryopreservation, encapsulation and promotion of shoot production of embryonic axes of a recalcitrant species Ekebergia capensis, Sparrm. Cryo Letters. 2006;27:5-16.

45. Steinmacher DA, Saldanha CW, Clement CR, Guerra MP. Cryopreservation of peach palm zygotic embryos. Cryo Letters 2007;28:13-22.

46. Sisunandar, Sopade

PA, Samosir YM, Rival A, Adkins SW. Dehydration improves cryopreservation of coconut
(Cocos nucifera L.). Cryobiology. 2010;61:289-296.

47. Mandal BB. Cryopreservation techniques for plant germplasm conservation. In: Mandal BB, Chaudhury R, Engelmann F, Bhag Mal, Tao KL, Dhillon BS, editors. Conservation Biotechnology of plant germplasma. NBPGR, New Delhi, India/IPGRI, Rome, Italy/ FAO, Rome, Italy. 2003;79-186.

48. Wu YJ, Huang XL, Xiao JN, Li XJ, Zhou $M D$, Engelmann F. Cryopreservation of mango (Mangifera Indica L.) embryonic cultures. Cryo Letters. 2003;24:303-314.

(C) 2021 Suryanti et al.; This is an Open Access article distributed under the terms of the Creative Commons Attribution License (http://creativecommons.org/licenses/by/4.0), which permits unrestricted use, distribution, and reproduction in any medium, provided the original work is properly cited. 